Research Report

\title{
Antagonism of glutamate receptors in the CA1 to perirhinal cortex projection prevents long-term potentiation and attenuates levels of brain-derived neurotrophic factor
}

\author{
John Kealy, Sean Commins* \\ Department of Psychology, National University of Ireland, Maynooth, Maynooth, Co. Kildare, Ireland
}

\section{A R T I C L E I N F O}

Article history:

Accepted 31 January 2009

Available online 13 February 2009

\section{Keywords:}

LTP

Hippocampus

Perirhinal cortex

AMPA

NMDA

BDNF

\begin{abstract}
A B S T R A C T
The CA1 to perirhinal cortex projection is one of multiple hippocampal-neocortical projections considered to be involved in memory consolidation. This projection has been shown to sustain long-term potentiation (LTP) following stimulation of CA1. Here we examined the pharmacological properties underpinning the plasticity observed in this projection. A stimulating electrode was inserted into the area CA1 and a recording electrode was inserted into the perirhinal cortex of urethane-anaesthetised Wistar rats. Rats $(n=6$ in each drug group) were administered with either saline (0.09\%), MK-801 (NMDA antagonist; $0.1 \mathrm{mg} / \mathrm{kg}$ ) or CNQX (AMPA/kainate antagonist; $1.5 \mathrm{mg} / \mathrm{kg}$ ). Baseline recordings were made for $10 \mathrm{~min}$ by stimulating area CA1 $(0.05 \mathrm{~Hz}$ stimulation protocol). High-frequency stimulation (HFS; $250 \mathrm{~Hz}$ ) was performed and post-HFS fEPSP recordings were made for $1 \mathrm{~h}(0.05 \mathrm{~Hz}$, as above). Baseline and post-HFS paired-pulse facilitation (PPF) recordings were performed across six different interpulse intervals. CA1 and perirhinal cortex tissue samples were taken from the stimulated and unstimulated hemispheres of each rat brain and analysed using a brain-derived neurotrophic factor (BDNF) ELISA. Results indicate that LTP was induced in the saline and MK-801 groups but not in the CNQX group; fEPSPs in the latter group rapidly returned to baseline levels following a short period of post-tetanic potentiation. Drug treatment and HFS had no effect on PPF levels. Drug treatment significantly reduced concentrations of both CA1 and perirhinal BDNF and prevented stimulation-induced increases in BDNF in CA1. This molecular and electrophysiological data suggests that LTP in the CA1-perirhinal cortex projection may require activation of postsynaptic AMPA/kainate receptors in order to sustain LTP.
\end{abstract}

(C) 2009 Elsevier B.V. All rights reserved.

\section{Introduction}

The hippocampal formation is an important structure for learning and memory (Scoville and Milner, 1957; O'Keefe and Nadel, 1978; Squire, 1992). Although not the actual site of storage for long-term memory, the hippocampal formation acts as the site of association of sensory information (Rolls,
1996) and is required to form long-term memories. Long-term storage is believed to occur in the neocortex with the hippocampal formation acting in an integrative role (Squire et al., 1984; Squire, 1992; McClelland et al., 1995; Squire and Alvarez, 1995).

Long-term potentiation (LTP) is a phenomenon first described in the rabbit hippocampus by Bliss and Lømo

\footnotetext{
* Corresponding author. Fax: +353 17084767.

E-mail address: Sean.Commins@nuim.ie (S. Commins).
} 
(1973) and is believed to be a model, if not the actual mechanism, for the neurophysiological underpinnings of memory. Two different mechanisms for the induction of LTP have been described in the literature. The first was identified in Schaffer collateral neurons in the hippocampus where it was found that LTP is dependent on the N-methyl-D-aspartic acid glutamate receptor (NMDA receptor; Collingridge et al., 1983). The second mechanism for LTP was identified in hippocampal mossy fibre neurons, where LTP can occur in the absence of functional NMDA receptors (Harris and Cotman, 1986). This non-NMDA receptor-dependent form of LTP has since been found to be mediated by the kainate glutamate receptor (Castillo et al., 1997; Vignes and Collingridge, 1997; Bortolotto et al., 1999). Kainate-induced potentiation in mossy fibre neurons can be induced independently of the alphaamino-3-hydroxy-5-methyl-4-isoxazolepropionic acid glutamate (AMPA) receptor (Vignes and Collingridge, 1997).

A strong molecular correlate of increases in synaptic strength, LTP and memory are the neurotrophins, a group of proteins that include brain-derived neurotrophic factor (BDNF), nerve growth factor (NGF), neurotrophin-3 and -4 (NT3 and NT4 respectively). BDNF (Barde et al., 1982) is a protein that is necessary for neuronal growth in the developing brain (see Klein, 1994 for review) and also plays a role in synaptic plasticity (Korte et al., 1995; Kang and Schuman, 1995a; 1995b; Bramham and Messaoudi, 2005; Lynch et al., 2007). BDNF signals via its specific receptor, tropomyosin receptor kinase B (TrkB; Squinto et al., 1991, Bramham et al., 2008), or the low affinity neurotrophin receptor, p75 (Rodriguez-Tébar et al., 1990). Learning (Falkenberg et al., 1992; Kesslak et al., 1998; 2003; Mizuno et al., 2000), exercise (Neeper et al., 1995; 1996; Widenfalk et al., 1999) and high-frequency stimulation of the brain (Patterson et al., 1992; Castrén et al., 1993; Dragunow et al., 1993) all give rise to increases in BDNF expression. For example, stimulation protocols that induce late phase LTP are known to correlate with sustained BDNF release, indeed, late phase LTP is impaired following disruption of BDNF-TrK interactions (Aicardi et al., 2004; Santi et al., 2006). In addition, BDNF knockout mice show significantly weaker LTP in area CA1 of the hippocampus compared to wild types (Korte et al., 1995). However, deficits in LTP in BDNF knockout mice can be reversed by the application of exogenous recombinant BDNF (Korte et al., 1996; Patterson et al., 1996). Blockade of the TrkB receptor in the hippocampus can also impair the induction of LTP following theta-burst stimulation (TBS) and post-tetanic blockade of the TrkB receptor disrupts LTP maintenance (Kang et al., 1997).

Using the NMDA receptor antagonist (+)-5-methyl-10,11dihydro-5H-dibenzo-[a,d]cyclo-hepten-5,10-imine-maleate (MK-801), blockade of LTP induction in dentate granule cells of the hippocampus also blocks the concurrent increases in BDNF expression (Dragunow et al., 1993). Application of BDNF in the hippocampus has been shown to potentiate synaptic transmission via the TrkB receptor, although this BDNFinduced potentiation appears to occur independently of NMDA receptor activation (Kang and Schuman, 1995a; 1995b). It has however also been demonstrated that BDNF enhances phosphorylation of the hippocampal NMDA subunits NR1 and NR2B (Lin et al., 1998; Suen et al., 1997) in the postsynaptic density (PSD) and that the extent of PSD NR2B phosphorylation is similar to that of post-LTP induction suggesting that BDNF may directly modulate LTP via the NMDA receptor. Indeed, there is also evidence of BDNF interaction with the AMPA receptor during synaptic transmission and plasticity. Wu et al. (2004), for example, have demonstrated that BDNF may also enhance phosphorylation of the AMPA receptor GluR1 via changes in the NMDA receptor function (Wu et al., 2004). While the AMPA-type glutamate receptor modulators (the ampakines) have been shown to both increase BDNF protein levels and attenuates the aged-related impairment of LTP observed in hippocampal slices of middle-aged animals (Rex et al., 2006). However, in a more recent study examining the effects of BDNF on synaptic transmission, Madara and Levine (2008) suggest that BDNF does not act on postsynaptic AMPA receptors but rather it simultaneously modulates both pre and postsynaptic NMDA receptors.

Blocking the glutamate receptors pharmacologically have also led to impairment in a variety of memory tasks. For example, the NMDA receptor is implicated in both spatial memory (Morris et al., 1986; Larkin et al., 2008) and object recognition memory (Winters and Bussey, 2005b; de Lima et al., 2005). Administration of AP-5 (Winters and Bussey, 2005b; Barker et al., 2006) or MK-801 (de Lima et al., 2005; Nilsson et al., 2007) either pre- or post-training, for example, has been shown to impair rats' performance in object recognition tasks. There is also evidence for the involvement of the AMPA receptor in object recognition memory, administration of 6cyano-2,3-dihydroxy-7-nitro-quinoxaline (CNQX) to rats either pre- or post-training results in an impairment in performance in an object recognition task (Winters and Bussey, 2005b).

The perirhinal cortex is located on the dorsal and ventral sides of the rostral region of the posterior end of the rhinal fissure (Burwell et al., 1995; Burwell, 2000; 2001) and also seems to play a time-dependent role in spatial learning (Nagahara et al., 1995; Liu and Bilkey, 1998); is active with exposure to novel environments (Liu and Bilkey, 2001); is involved in timedependent memory of trial specific information (Wiig and Burwell, 1998) and may also be involved in long-term memory of spatial learning (Ramos, 2002; Ramos and Vaquero, 2005). Further, the perirhinal cortex is involved in object recognition memory (Liu and Bilkey, 2001; Winters and Bussey, 2005a; Hannesson et al., 2005). In rats, temporary lesions of the perirhinal cortex using lidocaine lead to deficits in object recognition task performance (Winters and Bussey, 2005a) and antagonism of NMDA, AMPA and kainate receptors in the perirhinal cortex also lead to deficits in object recognition task performance (Winters and Bussey, 2005b, Barker et al., 2006). These studies implicate the perirhinal cortex in encoding, retrieval and consolidation of memories, especially object recognition memories (Winters and Bussey, 2005a; 2005b). In addition, it seems that NMDA and kainate receptors may also have different functional roles in object recognition memory; with kainate receptors mediating object recognition memory at a short but not a long delay and NMDA receptors mediating such memory at a long but not a short delay (Barker et al., 2006). Barker and Warburton (2008) have also demonstrated that perirhinal NMDA receptors are required for acquisition of short-term object-in-place associative memories. 
Given the importance of the perirhinal cortex in various forms of memory and that the back projections from the hippocampus to the neocortex may participate in consolidation of memories, it is important to examine these projections in more detail. Anatomical studies utilising both anterograde tracing (Swanson and Cowan, 1977; Van Groen and Wyss, 1990) and retrograde tracing (Deacon et al., 1983) have shown the presence of outputs from the septal region of the area CA1 to the deep layers of the caudoventral perirhinal cortex, completely avoiding the entorhinal cortex. The perirhinal cortex also provides excitatory inputs to both the area CA1 and the subiculum (Naber et al., 1999; 2001b). In addition, the perirhinal cortex can connect with the hippocampus through reciprocal connections with the entorhinal cortex (Burwell and Amaral, 1998a; 1998b; Burwell, 2001) and the entorhinal cortex is in turn reciprocally connected to the hippocampus (Deacon et al., 1983; Kloosterman et al., 2003; Craig and Commins, 2005; 2006).

Despite these studies there has been little work describing either the electrophysiological or the pharmacological properties of these projections. Recently, Craig and Commins (2005; 2006) have reported that projections from both the area CA1 and the subiculum to the entorhinal cortex can sustain LTP while Cousens and Otto (1998) succeeded in inducing LTP in the CA1 to perirhinal cortex projection using theta burst stimulation (TBS). Initial work in our lab supports the findings of Cousens and Otto; the CA1 to perirhinal pathway can sustain LTP for at least an hour following $250 \mathrm{~Hz}$ high-frequency stimulation (HFS) (Kealy and Commins, unpublished observations), suggesting that the pathway going from the area CA1 to the perirhinal cortex is electrophysiologically active and could play a role in memory formation.

The current study aims to extend our own preliminary findings and those of Cousens and Otto (1998) by examining plasticity in the CA1 to perirhinal cortex projection and also examining the pharmacological properties of this projection using the NMDA receptor antagonist MK-801 and the AMPA/ kainate receptor antagonist CNQX (Honoré et al., 1988). Further, by using paired-pulse facilitation (PPF), a technique often used to determine the locus of change following potentiation, we wish to determine whether the potentiation observed in the CA1 to perirhinal cortex projection is pre- or postsynaptic in nature. Finally, given the strong role of neurotrophins in learning and memory, especially BDNF, changes in plasticity will be correlated with changes in BDNF concentrations in the area CA1 and in the perirhinal cortex using an enzyme-linked immunosorbent assay (ELISA).

\section{Results}

An initial characterisation of the evoked response obtained in the perirhinal cortex following a single pulse stimulation of CA1 delivered at $0.05 \mathrm{~Hz}(n=10)$ revealed a mean amplitude of $-6.78 \mathrm{mV}( \pm 0.74)$, mean slope of the downward deflection of $-0.825 \mathrm{mV} / \mathrm{s}( \pm 0.091)$ with a latency of the peak amplitude of $8.27 \pm 0.68 \mathrm{~ms}$. Although we found a significant increase in both fEPSP peak amplitude and slope during potentiation and facilitation (see below) we decided to limit our analyses to the slope measures consistent with the work of Cousens and Otto (1998).

We then conducted a small set of control experiments to examine the effect of CNQX on baseline fEPSP responses $(n=3)$. We recorded baseline fEPSPs for $10 \mathrm{~min}(100 \pm 0.96 \%)$ and then injected each rat with CNQX (dose: $1.5 \mathrm{mg} / \mathrm{kg}$; concentration of solution: $1.5 \mathrm{mg} / \mathrm{ml}$; actual volume of injection: $1 \mathrm{ml} / \mathrm{kg}$ ). We continued to record fEPSPs for a further $3 \mathrm{~h}$. fEPSP slopes (averaged over $10 \mathrm{~min}$ ) at 1, 2 and $3 \mathrm{~h}$ post-injection were $97.30 \pm 1.85 \%, 96.14 \pm 1.73 \%$ and $98.26 \pm 1.83 \%$ respectively. A repeated measures ANOVA was conducted on these data demonstrating no significant change in baseline response over the recording period $(F=1.063 ; d f=3,27 ; p>0.05)$.

\subsection{Effects of glutamate receptor blockade on LTP}

To examine the effects of glutamate blockade on LTP, a $3 \times 4$ mixed factorial ANOVA was used with time analysed on 4 levels (-10-0 min, 0-10 $\mathrm{min}, 20-30 \mathrm{~min}$ and 50-60 $\mathrm{min}$ ) as a within-groups measure. Drug treatment was analysed on 3 levels (saline, MK-801 and CNQX) as a between-groups measure. Overall, there was a significant effect of time $(F=96.652 ; d f=3,81 ; p<0.001)$. Drug treatment was also shown to have a significant effect $(F=78.723 ; d f=2,27$; $p<0.001)$. In addition, an interaction effect between drug treatment and time was shown $(F=13.581 ; d f=6,81 ; p<0.01)$. Across the full length of the experiment (Fig. 1), saline-treated animals showed significantly higher levels of potentiation compared to CNQX-treated animals $(p<0.001)$. Similarly, MK801-treated animals showed significantly more potentiation compared to CNQX-treated animals $(p<0.001)$. There was no overall significant difference between saline-treated and MK801-treated animals $(p>0.05)$.

Looking at the effects of drug treatment at different times during recording showed some significant differences (Fig. 1). Baseline levels (10 to $1 \mathrm{~min}$ pre-HFS) showed no significant differences $(p>0.05)$ but there were significant differences observed between drug treatments during post-tetanic potentiation (PTP; 0 to $10 \mathrm{~min}$ post-HFS). CNQX-treated animals showed significantly lower levels of PTP compared to salinetreated animals $(p<0.01)$ and MK-801-treated animals $(p<0.001)$. There were no significant differences between saline- and MK-801-treated animals ( $p>0.05)$.

Looking at middle-LTP (21 to 30 min post-HFS) in more detail reveals that CNQX-treated animals showed significantly lower levels of potentiation compared to saline-treated animals $(p<0.001)$ and MK-801-treated animals $(p<0.001)$. Late-LTP (51 to $60 \mathrm{~min}$ post-HFS) showed a further difference between the groups. At this stage, CNQX-treated animals again showed significantly lower levels of potentiation compared to saline-treated animals $(p<0.001)$ and MK-801treated animals $(p<0.001)$. In addition, MK-801-treated animals also showed significantly lower levels of potentiation compared to saline-treated animals $(p<0.001)$.

\subsection{Effects of glutamate receptor blockade on baseline and post-HFS PPF}

Prior to $250 \mathrm{~Hz}$ HFS, PPF recordings were made at six different interpulse intervals (IPI; $20 \mathrm{~ms}, 40 \mathrm{~ms}, 60 \mathrm{~ms}, 120 \mathrm{~ms}$, 


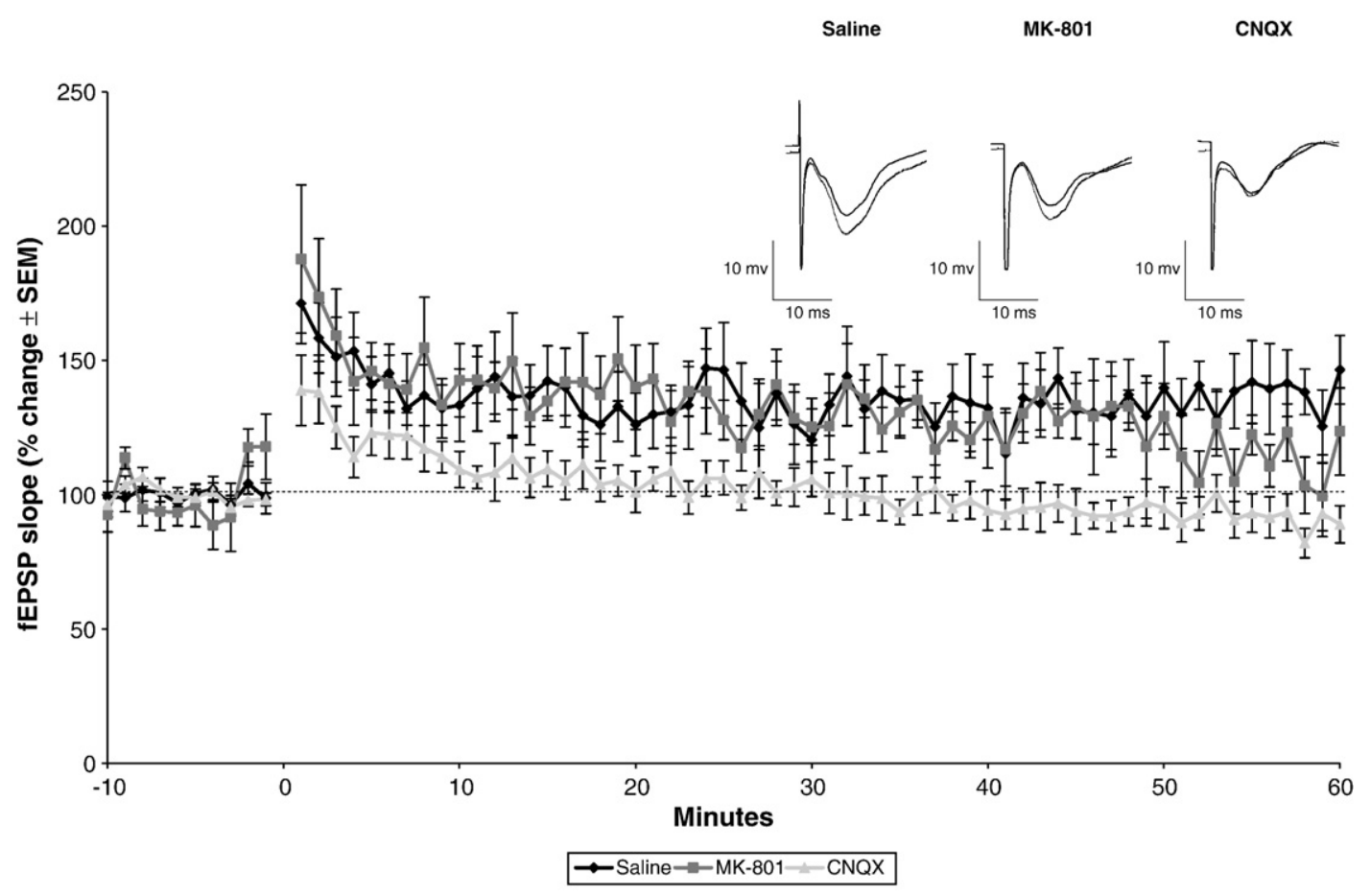

Fig. 1-Effect of glutamate receptor antagonism on long-term potentiation (LTP) induced by $250 \mathrm{~Hz}$ high-frequency stimulation (HFS). Saline-treated animals ( $n=6$, black diamonds) showed LTP lasting for at least $1 \mathrm{~h}$. MK-801-treated animals ( $n=6$, dark grey squares) showed LTP lasting approximately $50 \mathrm{~min}$ before beginning to deteriorate. CNQX-treated animals ( $n=6$, light grey triangles) showed LTP lasting only approximately $25 \mathrm{~min}$ before dropping below baseline levels. Each point represents an average of three fEPSP slopes recorded over $1 \mathrm{~min}$ and data is expressed as a percentage of baseline fEPSP slopes where baseline is approximately $100 \%$. Inset are representative fEPSP traces from the three drug groups showing baseline fEPSPs (-10 min; solid line) and post-HFS fEPSPs (+30 min; dashed line).

$240 \mathrm{~ms}$ and $480 \mathrm{~ms}$; a within-groups measure) in all three drug groups (saline, MK-801 and CNQX; a between groups measure). A $3 \times 6 \times 2$ mixed factorial ANOVA confirmed significant effects for interval $(F=25.961 ; d f=5,75 ; p<0.001)$ and for facilitation (pulse1 vs pulse2; $F=60.019 ; d f=1,15$; $p<0.001)$ but there were no significant effects found for drug treatment $(F=0.143 ; d f=2,15 ; p>0.05)$. There were no interaction effects for interval and drug treatment $(F=0.809$; $d f=10,75 ; p>0.05)$ and facilitation and drug treatment $(F=0.143 ; d f=2,15 ; p>0.05)$ but there was an interaction effect for interval and facilitation $(F=25.961 ; d f=5,75$; $p<0.001)$. The results showed that significant facilitation occurs at shorter intervals, peaking with a $40 \mathrm{~ms}$ interval in saline- and MK-801-treated animals and with a $60 \mathrm{~ms}$ interval in CNQX-treated animals (Fig. 2a). Following dependent $t$-tests, significant facilitation was found for $40 \mathrm{~ms}$, $60 \mathrm{~ms}$ and $120 \mathrm{~ms}$ IPIs in all drug treatment groups $(p<0.05)$, for $20 \mathrm{~ms}$ IPI for the saline- and CNQX-treated groups $(p<0.05)$ and for $240 \mathrm{~ms}$ IPI for CNQX-treated animals alone $(p<0.05)$ PPF tapered out at longer intervals; there was no significant facilitation seen in the second fEPSP response to the second stimulus compared to the first for the $240 \mathrm{~ms}$ (in saline- and MK-801-treated animals) and $480 \mathrm{~ms}$ intervals (all drug treatment groups; Fig. 2a).

We then compared the percentage facilitation obtained in each treated group and at each interval $60 \mathrm{~min}$ post-HFS to the baseline facilitation levels (Fig. 2b). A $2 \times 3 \times 6$ mixed factorial ANOVA was employed, again with IPI as a withingroups measure and drug treatment as a between-groups measure and also with time (baseline and post-HFS) as a within-groups measure. No overall effects were found for drug treatment $(F=1.608 ; d f=1,15 ; p>0.05)$ but significant effects were found for time $(F=7.002 ; d f=1,15 ; p<0.05)$ and interval $(F=28.474 ; d f=5,75 ; p<0.001)$. However, no interaction effects were found for time and drug treatment $(F=2.523$; $d f=2,15 ; p>0.05)$, for interval and group $(F=28.474 ; d f=10 ; 75$; $p>0.05)$ or for time and interval $(F=1.586 ; d f=5,75 ; p>0.05)$. Dependent $t$-tests revealed that there were no significant changes observed in the saline- and CNQX-treated groups and in the MK-801-treated group there was only a significant attenuation in facilitation seen following HFS at the $20 \mathrm{~ms}$ interval (Fig. 2b).

\subsection{Effects of glutamate receptor blockade on BDNF levels}

We first compared BDNF levels in the area CA1 of the hippocampus using a $2 \times 3$ ANOVA, with hemisphere (stimulated and unstimulated hemispheres) as the within-group measure and drug treatment (saline, MK-801 and CNQX) as the between-groups measure (Fig. 3a). There was an overall effect for hemisphere with the area CA1 of the stimulated hemisphere showing significantly higher levels of BDNF compared to the area CA1 of the unstimulated hemisphere $(F=12.787$; $d f=1,15 ; p<0.01)$. We also found an overall effect for drug 
(a)
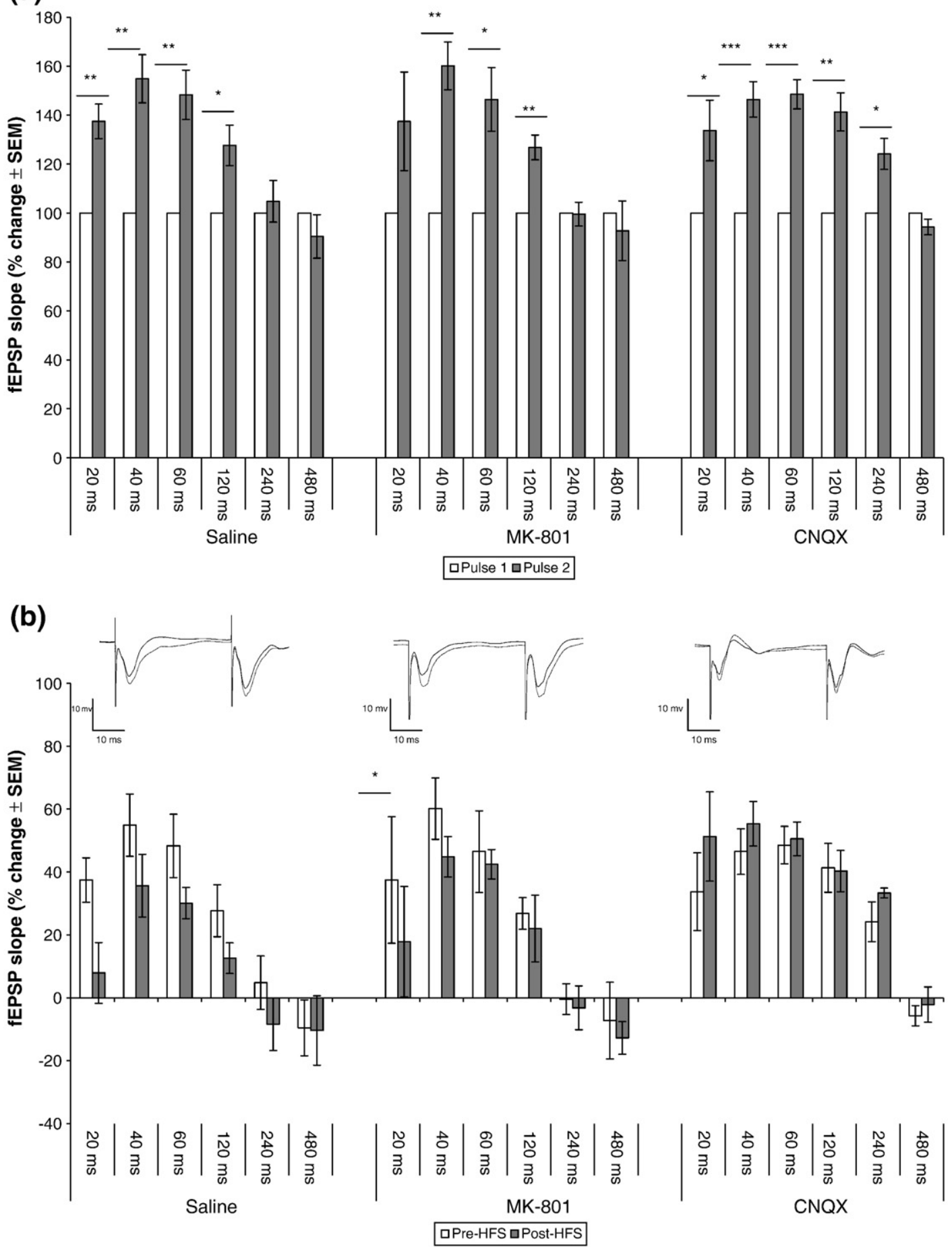

Fig. 2-(a) The effect of paired-pulse facilitation (PPF) at six interpulse intervals (IPIs) in the baseline condition. PPF peaked at $40 \mathrm{~ms}$ in the saline- and MK-801-treated groups and at $60 \mathrm{~ms}$ in the CNQX-treated group. PPF tapered off at longer intervals. (b) Comparison between baseline and post-HFS levels of facilitation at the six IPIs. ${ }^{*} p<0.05 ;{ }^{* *} p<0.01 ;{ }^{* * *} p<0.001$. Inset are representative fEPSP traces recorded at the $60 \mathrm{~ms}$ interval for each group in the baseline (-10 min; solid line) and post-HFS (+60 min; dashed line) conditions.

treatment $(F=66.884 ; d f=2,15 ; p<0.001)$. Post-hoc analysis (Tukey test) showed that the MK-801- and CNQX-treated groups showed significantly lower levels of BDNF in the area CA1 compared to the saline-treated group $(p<0.001)$. There was also an interaction effect between drug treatment and hemisphere in the area CA1 $(F=3.564 ; d f=2,15 ; p=0.05)$. Further dependent t-tests demonstrated that in the salinetreated group there was a significant increase in BDNF levels 

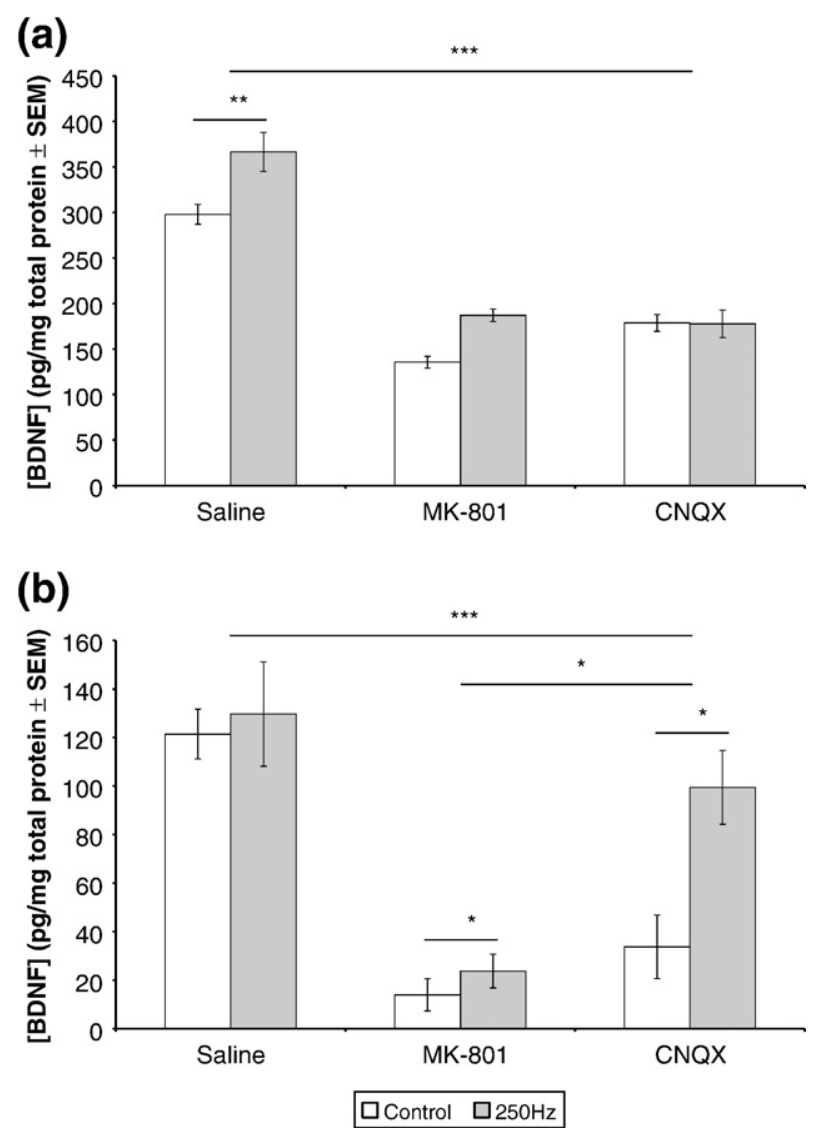

Fig. 3-Effect of glutamate receptor antagonism and $250 \mathrm{~Hz}$ high-frequency stimulation (HFS) on BDNF levels in (a) the area CA1 and (b) the perirhinal cortex. Saline-treated animals showed a significant increase in BDNF levels in the area CA1 following $250 \mathrm{~Hz}$ HFS. No significant increases in BDNF in the area CA1 were found in either drug treated group. In the perirhinal cortex there were significant increases in BDNF levels in both the MK-801- and CNQX-treated groups but not in the saline-treated group following HFS. There was no significant difference between perirhinal BDNF levels in the stimulated hemisphere in the CNQX group compared to the saline group. ${ }^{*} p<0.05 ;{ }^{* *} p<0.01$.

in the stimulated side of the area CA1 compared to the unstimulated side $(t=-4.708 ; d f=5 ; p<0.01)$. No other differences were noted.

We compared the effects of drug treatment within each hemisphere using a one-way ANOVA. Within the area CA1 of the unstimulated hemisphere there was a significant effect found for drug treatment ( $F=87.178 ; d f=2,15 ; p<0.001)$. Tukey post-hoc tests revealed that BDNF levels were significantly higher in the saline-treated group compared to the MK-801and CNQX-treated groups ( $p<0.001$ for both) and that BDNF levels in the CNQX-treated group were significantly higher than those in the MK-801-treated group $(p<0.05)$. Similarly there was an effect for drug treatment in the area CA1 of the stimulated hemisphere $(F=30.680 ; d f=2,15 ; p<0.001)$. Again, Tukey post hoc tests showed that there were significantly higher levels of BDNF in the saline-treated group compared to the MK-801- and CNQX-treated groups ( $p<0.001$ for both) but no significant differences between MK-801- and CNQX-treated groups $(p>0.05)$.

We next compared BDNF levels in the perirhinal cortex, again using a $2 \times 3$ ANOVA with hemisphere (stimulated and unstimulated hemispheres) as the within-group measure and drug treatment (saline, MK-801 and CNQX) as the betweengroups measure (Fig. 3b). There was an overall effect for hemisphere with the perirhinal cortex of the stimulated hemisphere showing significantly higher levels of BDNF compared to the perirhinal cortex of the unstimulated $(F=10.952 ; d f=1,15 ; p<0.01)$.

Again, an overall effect for drug treatment on BDNF levels was observed $(F=23.083 ; d f=2,15 ; p<0.001)$. Post-hoc analysis (Tukey test) showed that compared to the saline-treated group, the MK-801- and CNQX-treated groups again showed significantly lower levels of perirhinal BDNF $(p<0.001$ and $p<0.01$ respectively). In addition, overall BDNF levels in the MK-801-treated group were significantly lower than the CNQX-treated group $(p<0.05)$. There was an interaction effect between drug treatment and HFS in the perirhinal cortex $(F=5.036 ; d f=2,15 ; p<0.05)$. Dependent t-tests demonstrated that in the MK-801 group there were significantly higher levels in the stimulated hemisphere compared to the unstimulated hemisphere $(t=-2.762 ; d f=5 ; p<0.05)$. A similar pattern was observed in the CNQX-treated group ( $t=-3.480 ; d f=5 ; p<0.05)$.

We again compared the effects of drug treatment within each hemisphere using a one-way ANOVA. Within the perirhinal cortex of the unstimulated hemisphere there was a significant effect found for drug treatment $(F=30.522$; $d f=2$, $15 ; p<0.001)$. Tukey post-hoc tests revealed that BDNF levels were significantly higher in the saline-treated group compared to the MK-801- and CNQX-treated groups $(p<0.001$ for both) but no significant differences were found between the MK-801- and the CNQX-treated groups $(p<0.05)$. Similarly there was an effect for drug treatment in the perirhinal cortex of the stimulated hemisphere $(F=12.055 ; d f=2,15 ; p<0.01)$. Tukey post hoc tests showed that there were significantly higher levels of BDNF in the stimulated side of the perirhinal cortex in the saline-treated group compared to the MK-801treated group $(p<0.01)$ but there were no significant differences between saline- and CNQX-treated groups $(p>0.05)$. However, there were significantly higher levels of perirhinal BDNF in the stimulated hemisphere in the CNQX-treated group compared to the MK-801-treated group $(p<0.05)$.

\section{Discussion}

Here we demonstrate (see also Cousens and Otto, 1998) that the monosynaptic projection from the area CA1 to the perirhinal cortex is capable of sustaining LTP. This finding has important implications both in terms of memory research and the spread of epileptiform activity generated in the hippocampal regions. Indeed, this combined with our previous work demonstrating the capabilities of the CA1 to entorhinal cortex and subiculum to entorhinal cortex projections of sustaining plasticity (Craig and Commins, 2005; 2006) suggests multiple routes by which long-term memory can be consolidated in the neocortex. As area CA1 is one of the primary output structures of the hippocampus (Van Groen and 
Wyss, 1990; Amaral et al., 1991; Naber et al., 2001a; Amaral and Lavenex, 2007), demonstrating plasticity (short-term and longterm) here may provide a possible route and mechanism for information to be consolidated to long-term memory and may also provide routes for temporal lobe epilepsy to spread (Paré et al., 1992; Wozny et al., 2005).

Glutamate receptors of various kinds have been shown to have a central role in LTP (Collingridge et al., 1983; Castillo et al., 1997) and in memory formation (Morris et al., 1986). In the current studies, we demonstrate that the potentiation induced in this pathway can be blocked by CNQX and not MK-801, perhaps suggesting that the potentiation observed in this pathway is AMPA/kainate receptor-mediated rather than NMDA receptor-mediated. Although it should be noted that we observed a lowering of potentiation in the MK-801-treated group at $50 \mathrm{~min}$ post-HFS, indicating that there may also be some NMDA receptor influence at a longer time period. This finding that NMDA and AMPA/kainate receptors may perform different roles controlling plasticity in this projection demonstrates the complexity of the hippocampal circuit in terms of the types of potentiation observed in the various pathways and may suggest different functions for the different pathways. For example, NMDA receptor-mediated pathways include the Schaffer collateral (Collingridge et al., 1988, 1983), the perforant pathway (Wu et al., 2001) and the CA1 to subiculum pathway (Wozny et al., 2008) while kainate receptors are known to mediate potentiation in the mossy fibre pathway (Bortolotto et al., 1999). Bearing in mind that CNQX is an antagonist of both AMPA and kainate receptors (Honoré et al., 1988), we are as yet unable to say whether the CA1 to perirhinal cortex pathway should be classed with the mossy fibre pathway as a kainate receptor-mediated pathway (Bortolotto et al., 1999) or as an AMPA receptor-mediated pathway.

In addition to the type of LTP that is induced, the locus of change following potentiation has been much debated. One method in determining the locus of change following potentiation is by comparing levels of PPF post-HFS to baseline levels of facilitation (McNaughton, 1982; Larkman et al., 1992; Schulz et al., 1994; Commins et al., 1998). PPF is considered to be mainly presynaptic in nature; therefore if with potentiation there is a change in the facilitation strength, then it is possible that this potentiation contains at least some component of a presynaptic mechanism (McNaughton, 1982; Larkman et al., 1992; Schulz et al., 1994). Here we report no significant change in facilitation $1 \mathrm{~h}$ post-HFS in the saline group, suggesting that the potentiation observed in this pathway may be largely due to postsynaptic rather than presynaptic factors (Commins et al., 1998).

We initially observed that baseline PPF remained similar irrespective of drug treatment, suggesting that this short-term facilitation effect is not mediated by glutamate receptors. This would be expected as PPF is known to result from residual calcium in the presynaptic terminal following rapid activation of ion-gated $\mathrm{Ca}^{2+}$ channels (Wu and Saggau, 1994). Furthermore, at $60 \mathrm{~min}$ post-HFS we also found no significant change in facilitation in any of the drug treated groups, again suggesting that the potentiation observed is mainly postsynaptic in nature (Commins et al., 1998). Bearing this in mind, we did observe an attenuation of the PTP response (0-10 min post-HFS, Fig. 1) in the CNQX-treated group. PTP is also known to be a presynaptic event where the strength of the fEPSP is increased due to raised levels of neurotransmitter being released (Hubbard, 1963). This attenuation of PTP in the CNQX group suggests a small AMPA-dependent presynaptic component to the potentiation observed in the CA1 to the perirhinal cortex pathway.

Molecularly, saline-treated animals showed LTP and increased BDNF levels in area CA1 in the stimulated hemisphere. Although some authors demonstrate that unilateral LTP can trigger BDNF, trkC and nerve growth factor increases bilaterally in the hippocampal region (Bramham et al., 1996), we cannot rule out the possibility of an increase in BDNF in the unstimulated hemisphere in our experiment as well, we can only suggest for now that the BDNF expression was enhanced in the stimulated hemisphere compared to the unstimulated side. Conversely, IP injection of either MK-801 or CNQX reduced $\mathrm{BDNF}$ concentrations in both the area CA1 and the perirhinal cortex generally. Stimulation of the hippocampal formation has been shown in many other studies to lead to an increase in BDNF levels (Castrén et al., 1993; Gooney and Lynch, 2001). It has also been shown that BDNF (Korte et al., 1995; 1996; Patterson et al., 1996; Gooney and Lynch, 2001) and activation of the TrkB receptor (Kang et al., 1997; Minichiello et al., 2002) play large roles in the induction of LTP. As BDNF production was inhibited equally in both of our drugs groups, this suggests that glutamatergic signalling is required for BDNF expression (Dragunow et al., 1993; Wetmore et al., 1994; Falkenberg et al., 1996, Kesslak et al., 2003). Our findings compare favourably with those of Dragunow et al. (1993) who found that not only did MK-801 block the induction of LTP in the perforant path but that it also lowered the expression of BDNF. In addition, we found that not only did these glutamate receptor antagonists reduce global levels of BDNF but that they also blocked stimulation-induced increases in BDNF concentrations in the area CA1. This mirrors the attenuation of learning-induced increases in BDNF expression following administration of MK-801 in rats (Kesslak et al., 2003). This again points to a possible necessity for glutamatergic signalling in BDNF expression.

In the perirhinal cortex, where evoked responses occurred, BDNF synthesis was also generally inhibited in both the MK801- and CNQX-treated groups. Interestingly, in the salinetreated group there were no significant differences observed between the stimulated and unstimulated hemispheres. This may be explained by the work by Aicardi et al. (2004) where increases in the secretion of perirhinal BDNF levels following TBS in slices have been described. In their study, the induction of LTP leads to an increase in BDNF secretion in the 5-12 min following TBS (Aicardi et al., 2004); any increases in BDNF in the perirhinal cortex of the saline group may have been secreted by the time we took our tissue samples for analysis (i.e. over an hour post-HFS).

Nevertheless both MK-801- and CNQX-treated groups showed significantly higher levels of BDNF in the stimulated hemisphere compared to the unstimulated hemisphere. Of particular interest are the perirhinal BDNF levels in the stimulated hemisphere of the CNQX-treated group where they increased to a level not significantly different to those of the saline controls (i.e. reversing the drug-induced decreases in BDNF levels). This differs from Aicardi et al.'s experiment 
(2004) detailed above where, converse to the situation in the saline group, increased levels of BDNF were detected over an hour post-HFS in our study (Figs. 3a and b) compared to an increase lasting only 5-12 min in Aicardi et al.'s study. These differences might be explained by the fact that Aicardi et al. (2004) measured secreted BDNF from slices while we analysed homogenised tissue samples and as such may have detected unsecreted BDNF.

Overall, these findings suggest that the NMDA receptor and the AMPA/kainate receptors not only seem to have different functions in terms of electrophysiology in this pathway but that these differences extend to the expression of BDNF in these two brain areas. As some studies have shown behavioural differences between NMDA receptor antagonism and AMPA/kainate receptor antagonism (de Lima et al., 2005; Winters and Bussey, 2005b; Nilsson et al., 2007), the electrophysiological and molecular differences between the drug groups are expected. Furthermore, our results demonstrating an AMPA-mediated role in plasticity and BDNF changes perhaps should not be too surprising given that activation particularly of the non-NMDA receptors (AMPA and Kainate) result in an increased expression of neurotrophic factors, including BDNF (Zafra et al., 1990, 1992), while reciprocally BDNF via the TrkB receptor can increase the expression levels of AMPA receptors (Narisawa-Saito et al., 2002) which can enhance glutamatergic transmission in hippocampal cells (Lessmann et al., 1994; Levine et al., 1998). It is also known that the kinetics of AMPA-mediated BDNF activation are consistent with the known properties of AMPA receptors (Arai et al., 1996, 2002; Lockhart et al., 2007). In addition, sub-chronic administration of CX691 (an AMPA modulator) has been shown to elevate BDNF mRNA expression in both the whole and CA1 sub-region of the hippocampus (Woolley et al., 2009), while administration of another AMPA modulator (S18986) has been shown to enhance AMPA-mediated BDNF mRNA and protein expression in rat primary cortical neuronal cultures (Lockhart et al., 2007). These results along with ours suggest a close coupling of the AMPA receptor, BDNF and plasticity in the hippocampal-perirhinal projection.

In conclusion, this study confirms the findings of Cousens and Otto (1998) in that the projection from area CA1 to the perirhinal cortex can undergo changes in synaptic strength and the induction of LTP in this projection is reliant on AMPA/ kainate receptors. Moreover, from our PPF data, the changes in plasticity appear to be mainly postsynaptic in nature. Finally, BDNF appears to play a role in these changes in plasticity. These factors all add weight to the idea that this back projection may be a route for information to pass from the hippocampus to the neocortex, a necessity for both consolidation of long-term memories and for the spread of epileptiform activity.

\section{Experimental procedures}

\subsection{Surgery}

Adult male Wistar rats ( $n=18$; approximately 3 months old; weight: 300-400 g; Biomedical Unit; University College Dublin) were divided into three different groups. All animals were anaesthetised using urethane (ethyl carbamate; $1.5 \mathrm{mg} / \mathrm{kg}$; Sigma; administered via intraperitoneal (IP) injection) and mounted on a stereotaxic frame. An incision was made to expose the skull and burr holes were made to allow the electrodes to be inserted into the correct coordinates (Paxinos and Watson, 2005).

A stainless bipolar stimulating electrodes ( $50 \mu \mathrm{m}$ diameter), insulated apart from the tip, were aimed at the area CA1. Stainless wire recording electrodes (50 $\mu \mathrm{m}$ diameter) were aimed at the perirhinal cortex. Coordinates for both electrodes were based on the work of Cousens and Otto (1998); the stimulating electrode (CA1) was inserted $6.3 \mathrm{~mm}$ posterior to Bregma, $5.5 \mathrm{~mm}$ lateral to the midline and lowered to a depth of $2.2 \mathrm{~mm}$ measured from the surface of the brain. The recording electrode (perirhinal cortex) was inserted $5.2 \mathrm{~mm}$ posterior to Bregma, $4.3 \mathrm{~mm}$ lateral to the midline and lowered to a depth of $5.0 \mathrm{~mm}$ measured from the surface of the brain. The recording electrode was inserted at an angle of $17^{\circ}$ to increase the chances of hitting the correct population of cells that are part of the monosynaptic CA1 to perirhinal projection described by Cousens and Otto (1998).

One hour pre-tetanus (Morgan and Teyler, 1999), animals in the control group $(n=6)$ were administered with physiological saline $(0.1 \mathrm{ml} / 100 \mathrm{~g}$ body weight of $0.9 \% \mathrm{NaCl}$; Sigma, Ireland) and animals in the two experimental groups were given a glutamate receptor antagonist. The first group $(n=6)$ was administered with MK-801 (0.1 mg/kg body weight; Sigma, Ireland) and the second group $(n=6)$ was administered with CNQX (1.5 mg/kg body weight; Sigma, Ireland). All drugs were administered via i.p. injection. All animals were given approximately $40 \mathrm{~min}$ for the drug to enter their system before running the baseline PPF protocol, which meant that HFS could be performed approximately $1 \mathrm{~h}$ after drug administration. All drugs were made up fresh each week of the experiment and dose-sized aliquots were frozen for use throughout the week.

\subsection{Stimulation and data acquisition}

Signals were filtered between $1 \mathrm{~Hz}$ and $1 \mathrm{kHz}$ and then amplified (DAM-50 differential amplifier, World Precision Instruments, Hertfordshire, UK). Recordings were digitised using a PC running Spike2 (version 5.02, CED, Cambridge, UK) connected to a CED-1401 interface (CED, Cambridge, UK). In analysing the field excitatory postsynaptic potentials (fEPSPs), the slope of the response was measured (Gooney and Lynch, 2001). The slope was calculated from the middle two-thirds of the downward-deflecting component of the response.

Field EPSPs were evoked by stimulating with a square-wave (constant current pulse of $0.1 \mathrm{~ms}$ duration at a frequency of $0.05 \mathrm{~Hz}$ ). Although both Population Spike and fEPSPs were monitored, the incidences of the occurrence of population spike remained low (less than $5 \%$ of cases). By means of input/ output curve determination the maximum fEPSP was found for each individual animal. The intensity of stimulus was then set at a level that evoked a fEPSP slope of $50-60 \%$ of the maximum. This level is similar to that we have used before (Craig and Commins, 2005, 2006) on the CA1 and subicular to EC pathway and is similar to that used by other authors (Wöhrl 
et al., 2008) and Cousens and Otto (1998) on the CA1-perirhinal pathway.

Baseline paired-pulse facilitation (PPF) effects were measured after the electrodes were allowed to settle for $10 \mathrm{~min}$. Pairs of stimuli were then delivered with various interpulse intervals (IPIs) of 20, 40, 60, 120, 240 and $480 \mathrm{~ms}$. The PPF value was calculated by taking the value of six slopes values from the first stimuli out of the pairs (fEPSP1) for a given IPI and then normalising the average of six slope values from the second stimuli from the pairs (fEPSP2) with the resulting value expressed as a percentage (Commins et al., 1998). Following this, baseline measurements were induced at a rate of $0.05 \mathrm{~Hz}$ for another $10 \mathrm{~min}$.

LTP was then induced using a high-frequency stimulation (HFS) protocol. The HFS protocol consisted of three trains of stimuli (each lasting $200 \mathrm{~ms}$ ) at $250 \mathrm{~Hz}$ with an inter-train interval of $30 \mathrm{~s}$ (Gooney et al., 2002). Following HFS, recordings were made for an hour at $0.05 \mathrm{~Hz}$. Stimulus intensity during PPF and LTP induction was set at baseline intensity. Changes in fEPSP slope were assessed by measuring the slope of the response post-HFS compared to baseline response. Following this hour of recording, post-HFS PPF recordings were made using the same protocol as the pre-HFS PPF recordings.

\subsection{BDNF ELISA}

After each experiment, all animals were sacrificed by decapitation and their brains were immediately removed. The brains were then dissected on ice. An area of approximately $3 \mathrm{~mm}^{3}$ was removed from both area CA1 and perirhinal cortex that contained the final resting place of both the stimulating and recording electrode respectively. Equivalent sized areas in the unstimulated hemisphere were also removed for subsequent analysis. These samples were frozen and stored in Krebs- $\mathrm{CaCl}_{2} /$ dimethyl sulfoxide (DMSO) (Krebs solution was made using pre-prepared formula; all from Sigma, Ireland). All samples were later washed in Krebs$\mathrm{CaCl}_{2}$ and homogenised. $10 \mu \mathrm{l}$ aliquots of each sample were analysed using a Bradford protein assay in order to determine total protein concentration. Utilising these results, the sample solutions were normalised to be equal in concentration and an enzyme-linked immunosorbent assay (ELISA) for BDNF was performed using a BDNF $E_{\max }^{\circledR}$ ImmunoAssay System kit (Promega Corporation), following the manufacturer's protocol.

\subsection{Statistical analysis}

A series of dependent t-tests and mixed factorial analyses of variance (ANOVAs) with the appropriate post-hoc test (Tukey at the $5 \%$ level of significance) were performed using SPSS 13.0 for Windows (SPSS Software, Seattle, WA, USA). A star-rated system was used where appropriate $\left({ }^{*} p<0.05 ;{ }^{* *} p<0.01\right.$; $\left.{ }^{* * *} p<0.001\right)$.

\subsection{Ethical considerations}

Laboratory procedures for the maintenance and experimentation of animals conformed to the Department of Health (Ireland) guidelines and the European directive 86/609/EC.
Every effort was made to minimise the suffering and the number of animals used in this study.

\section{Acknowledgment}

This work has emanated from research conducted with the financial support of the Science Foundation of Ireland (SFI).

\section{R E F E R E N C E S}

Aicardi, G., Argilli, E., Capello, S., Santi, S., Riccio, M., Thoenend, H., Canossa, M., 2004. Induction of long-term potentiation and depression is reflected by corresponding changes in secretion of endogenous brain-derived neurotrophic factor. Proc. Natl. Acad. Sci. U.S.A. 101, 15788-15792.

Amaral, D.G., Dolorfo, C., Alvarez-Royo, P., 1991. Organization of CA1 projections to the subiculum: a PHA-L analysis in the rat. Hippocampus 1, 415-436.

Amaral, D.G., Lavenex, P., 2007. Hippocampal neuroanatomy. In: Anderson, P., Morris, R., Amaral, D., Bliss, T., O'Keefe, J. (Eds.), The Hippocampus Book. Oxford University Press, Oxford, pp. 37-114.

Arai, A., Guidotti, A., Costa, E., Lynch, G., 1996. Effect of the AMPA receptor modulator IDRA 21 on LTP in hippocampal slices. Neuroreport 7 (13), 2211-2215.

Arai, A.C., Xia, Y.F., Rogers, G., Lynch, G., Kessler, M., 2002. Benzamide-type AMPA receptor modulators form two subfamilies with distinct modes of action. J. Pharmacol. Exp. Ther. 303 (3), 1075-1085.

Barde, Y.A., Edgar, D., Thoenen, H., 1982. Purification of a new neurotrophic factor from a mammalian brain. EMBO J. 1, 549-553.

Barker, G.R.I., Warburton, E.C., 2008. NMDA receptor plasticity in the perirhinal and prefrontal cortices is crucial for the acquisition of long-term object-in-place associative memory. J. Neurosci. 28, 2837-2844.

Barker, G.R.I., Warburton, E.C., Koder, T., Dolman, N.P., More, J.C., Aggleton, J.P., Bashir, Z.I., Auberson, Y.P., Jane, D.E., Brown, M.W., 2006. The different effects on recognition memory of perirhinal kainate and NMDA glutamate receptor antagonism: implications for underlying plasticity mechanisms. J. Neurosci. 26, 3561-3566.

Bliss, T.V.P., Lømo, T., 1973. Long-lasting potentiation of synaptic transmission in the dentate area of the anaesthetized rabbit following stimulation of the perforant path. J. Physiol. 232, 331-356.

Bortolotto, Z.A., Clarke, V.R., Delany, C.M., Parry, M.C., Smolders, I., Vignes, M., Ho, K.H., Miu, P., Brinton, B.T., Fantaske, R., Ogden, A., Gates, M., Omstein, P.L., Lodge, D., Bleakman, D., Collingridge, G.L., 1999. Kainate receptors are involved in synaptic plasticity. Nature 402, 297-301.

Bramham, C.R., Messaoudi, E., 2005. BDNF function in adult synaptic plasticity: the synaptic consolidation hypothesis. Prog. Neurobiol. 76 (2), 99-125.

Bramham, C.R., Southard, T., Sarvey, J.M., Herkenham, M., Brady, L.S., 1996. Unilateral LTP triggers bilateral increases in hippocampal neurotrophin and trk receptor mRNA expression in behaving rats: evidence for interhemispheric communication. J. Comp. Neurol. 368 (3), 371-382.

Bramham, C.R., Worley, P.F., Moore, M.J., Guzowski, J.F., 2008. The immediate early gene arc/arg3.1: regulation, mechanisms, and function. J. Neurosci. 28 (46), 11760-11767.

Burwell, R.D., 2000. The parahippocampal region: corticocortical connectivity. Ann. N.Y. Acad. Sci. 911, 25-42. 
Burwell, R.D., 2001. Borders and cytoarchitecture of the perirhinal and postrhinal cortices in the rat. J. Comp. Neurol. 437, 17-41.

Burwell, R.D., Amaral, D.G., 1998a. The perirhinal and postrhinal cortices of the rat: interconnectivity and connections with the entorhinal cortex. J. Comp. Neurol. 391, 293-321.

Burwell, R.D., Amaral, D.G., 1998b. Cortical afferents of the perirhinal, postrhinal, and entorhinal cortices of the rat. J. Comp. Neurol. 398, 179-205.

Burwell, R.D., Witter, M.P., Amaral, D.G., 1995. Perirhinal and postrhinal cortices of the rat: a review of the neuroanatomical literature and comparison with findings from the monkey brain. Hippocampus, 5, 390-408.

Castrén, E., Pitkänen, M., Sirviö, J., Parsadanian, A., Lindholm, D., Thoenen, H., Riekinnen, P.J., 1993. The induction of LTP increases BDNF and NGF mRNA but decreases NT-3 mRNA in the dentate gyrus. Neuroreport 4, 895-898.

Castillo, P.E., Malenka, R.C., Nicoll, R.A., 1997. Kainate receptors mediate a slow postsynaptic current in hippocampal CA3 neurons. Nature 388, 182-186.

Collingridge, G.L., Kehl, S.J., McLennan, H., 1983. Excitatory amino acids in synaptic transmission in the Schaffer collateral-commissural pathway of the rat hippocampus. J. Physiol. 334, 33-46.

Collingridge, G.L., Herron, C.E., Lester, R.A., 1988. Synaptic activation of N-methyl-D-aspartate receptors in the Schaffer collateral-commissural pathway of rat hippocampus. J. Physiol. 399, 283-300.

Commins, S., Gigg, J., Anderson, M., O’Mara, S.M., 1998. Interaction between paired-pulse facilitation and long-term potentiation in the projection from the hippocampal area CA1 to the subiculum. Neuroreport 9, 4109-4113.

Cousens, G., Otto, T.A., 1998. Induction and transient suppression of long-term potentiation in the peri- and postrhinal cortices following theta-related stimulation of hippocampal field CA1. Brain Res. 780, 95-101.

Craig, S., Commins, S., 2005. Interaction between paired-pulse facilitation and long-term potentiation in the projection from hippocampal area CA1 to the entorhinal cortex. Neurosci. Res. 53, 140-146.

Craig, S., Commins, S., 2006. The subiculum to entorhinal cortex projection is capable of sustaining both short- and long-term plastic changes. Behav. Brain Res. 174, 281-288.

Deacon, T.W., Eichenbaum, H., Rosenberg, P., Eckmann, K.W., 1983. Afferent connections of the perirhinal cortex in the rat. J. Comp. Neurol. 220, 168-190.

de Lima, M.N., Laranja, D.C., Bromberg, E., Roeslef, R., Schröder, N., 2005. Pre- or post-training administration of the NMDA receptor blocker MK-801 impairs object recognition memory in rats. Behav. Brain Res. 156, 139-143.

Dragunow, M., Beilharz, E., Mason, B., Lawlor, P., Abraham, W., Gluckman, P., 1993. Brain-derived neurotrophic factor expression after long-term potentiation. Neurosci. Lett. 160, 232-236.

Falkenberg, T., Lindefors, N., Camilli, F., Metsis, M., Ungerstedt, U., 1996. Glutamate release correlates with brain-derived neurotrophic factor and trkB mRNA expression in the CA1 region of rat hippocampus. Molecular Brain Res. 42, 317-327.

Falkenberg, T., Mohammed, A.K., Henriksson, B., Persson, H., Winblad, B., Lindefors, N., 1992. Increased expression of brain-derived neurotrophic factor mRNA in rat hippocampus is associated with improved spatial memory and enriched environment. Neurosci. Lett. 138, 153-156.

Gooney, M., Lynch, M.A., 2001. Long-term potentiation in the dentate gyrus of the rat hippocampus is accompanied by brain-derived neurotrophic factor-induced activation of TrkB. J. Neurochem. 77, 1198-1207.

Gooney, M., Shaw, K., Kelly, A., Lynch, M.A., 2002. Long-term potentiation and spatial learning are associated with increased phosphorylation of TrkB and extracellular signal-regulated kinase (ERK) in the dentate gyrus: evidence for a role for brain-derived neurotrophic factor. Behav. Neurosci. 116, 455-463.

Hannesson, D.K., Howland, J.G., Pollock, M., Mohapel, P., Wallace, A.E., Corcoran, M.E., 2005. Anterior perirhinal cortex kindling produces long-lasting effects on anxiety and object recognition memory. Eur. J. Neurosci. 21, 1081-1090.

Harris, E.W., Cotman, C.W., 1986. Long-term potentiation of guinea pig mossy fiber responses is not blocked by N-methyl D-aspartate antagonists. Neurosci. Lett. 70, 132-137.

Honoré, T., Davies, S.N., Drejer, J., Fletcher, E.J., Jacobsen, P., Lodge, D., Nielsen, F.E., 1988. Quinoxalinediones: potent competitive non-NMDA glutamate receptor antagonists. Science 241, 701-703.

Hubbard, J.I., 1963. Repetitive stimulation at the mammalian neuromuscular junction, and the mobilization of transmitter. J. Physiol. 169, 641-662.

Kang, H.J., Schuman, E.M., 1995a. Long-lasting neurotrophininduced enhancement of synaptic transmission in the adult hippocampus. Science 267, 1658-1662.

Kang, H.J., Schuman, E.M., 1995b. Neurotrophin-induced modulation of synaptic transmission in the adult hippocampus. J. Physiol., Paris 89, 11-22.

Kang, H., Welcher, A.A., Shelton, D., Schuman, E.M., 1997. Neurotrophins and time: different roles for TrkB signaling in hippocampal long-term potentiation. Neuron 19, 653-664.

Kesslak, J.P., Chuang, K.R., Berchtold, N.C., 2003. Spatial learning is delayed and brain-derived neurotrophic factor mRNA expression inhibited by administration of MK-801 in rats. Neurosci. Lett. 353, 95-98.

Kesslak, J.P., So, V., Choi, J., Cotman, C.W., Gomez-Pinilla, F., 1998. Learning upregulates brain-derived neurotrophic factor messenger ribonucleic acid: a mechanism to facilitate encoding and circuit maintenance? Behav. Neurosci. 112, 1012-1019.

Klein, R., 1994. Role of neurotrophins in mouse neuronal development. FASEB J. 8, 738-744.

Kloosterman, F., Witter, M.P., Van Haeften, T., 2003. Topographical and laminar organization of subicular projections to the parahippocampal region of the rat. J. Comp. Neurol. 455, 156-171.

Korte, M., Carroll, P., Wolf, E., Brem, G., Thoenen, H., Bonhoeffer, T., 1995. Hippocampal long-term potentiation is impaired in mice lacking brain-derived neurotrophic factor. Proc. Natl. Acad. Sci. U.S.A. 92, 8856-8860.

Korte, M., Staiger, V., Griesbeck, O., Thoenen, H., Bonhoeffer, T., 1996. The involvement of brain-derived neurotrophic factor in hippocampal long-term potentiation revealed by gene targeting experiments. J. Physiol., Paris 90, 157-164.

Larkin, A.E., Fahey, B., Gobbo, O., Callaghan, C.K., Cahill, E., O’Mara, S.M., Kelly, Á.M., 2008. Blockade of NMDA receptors pretraining, but not post-training, impairs object displacement learning in the rat. Brain Res. 1199, 126-132.

Larkman, A., Hannay, T., Stratford, K., Jack, J., 1992. Presynaptic release probability influences the locus of long-term potentiation. Nature 360, 70-73.

Lessmann, V., Gottmann, K., Heumann, R., 1994. BDNF and NT-4/5 enhance glutamatergic synaptic transmission in cultured hippocampal neurones. Neuroreport. 6 (1), 21-25.

Levine, E.S., Crozier, R.A., Black, I.B., Plummer, M.R., 1998. Brain-derived neurotrophic factor modulates hippocampal synaptic transmission by increasing $\mathrm{N}$-methyl-D-aspartic acid receptor activity. Proc. Natl. Acad. Sci. U. S. A. 95 (17), 10235-10239.

Lin, S.Y., Wu, K., Levine, E.S., Mount, H.T., Suen, P.C., Black, I.B., 1998. BDNF acutely increases tyrosine phosphorylation of the NMDA receptor subunit $2 \mathrm{~B}$ in cortical and hippocampal postsynaptic densities. Brain Res. Mol. Brain Res. 55 (1), 20-27. 
Liu, P., Bilkey, D.K., 1998. Lesions of perirhinal cortex produce spatial memory deficits in the radial maze. Hippocampus 8, 114-121.

Liu, P., Bilkey, D.K., 2001. The effect of excitotoxic lesions centered on the hippocampus or perirhinal cortex in object recognition and spatial memory tasks. Behav. Neurosci. 115, 94-111.

Lockhart, B.P., Rodriguez, M., Mourlevat, S., Peron, P., Catesson, S., Villain, N., Galizzi, J.P., Boutin, J.A., Lestage, P., 2007. S18986: a positive modulator of AMPA-receptors enhances (S)-AMPAmediated BDNF mRNA and protein expression in rat primary cortical neuronal cultures. Eur. J. Pharmacol. 561 (1-3), 23-31.

Lynch, G., Rex, C.S., Gall, C.M., 2007. LTP consolidation: substrates, explanatory power, and functional significance. Neuropharmacology 52 (1), 12-23.

Madara, J.C., Levine, E.S., 2008. Presynaptic and postsynaptic NMDA receptors mediate distinct effects of brain-derived neurotrophic factor on synaptic transmission. J. Neurophysiol. 100 (6), 3175-3184.

McClelland, J.L., McNaughton, B.L., O'Reilly, R.C., 1995. Why there are complementary learning systems in the hippocampus and neocortex: insights from the successes and failures of connectionist models of learning and memory. Psychol. Rev. 102, 419-457.

McNaughton, B.L., 1982. Long-term synaptic enhancement and short-term potentiation in rat fascia dentate act through different mechanisms. J. Physiol. 324, 249-262.

Minichiello, L., Calella, A.M., Medina, D.L., Bonhoeffer, T., Klein, R., Korte, M., 2002. Mechanism of TrkB-mediated hippocampal long-term potentiation. Neuron 36, 121-137.

Mizuno, M., Yamada, K., Olariu, A., Nawa, H., Nabeshima, T., 2000. Involvement of brain-derived neurotrophic factor in spatial memory formation and maintenance in a radial arm maze test in rats. J. Neurosci. 20, 7116-7121.

Morgan, S.L., Teyler, T.J., 1999. VDCCs and NMDARs underlie two forms of LTP in CA1 hippocampus in vivo. J. Neurophysiol. 82, 736-740.

Morris, R.G., Anderson, E., Lynch, G.S., Baudry, M., 1986. Selective impairment of learning and blockade of long-term potentiation by an N-methyl-D-aspartate receptor antagonist, AP5. Nature 319, 774-776.

Naber, P.A., Witter, M.P., da Silva, F.H.L., 1999. Perirhinal cortex input to the hippocampus in the rat: evidence for parallel pathways, both direct and indirect. A combined physiological and anatomical study. Eur. J. Neurosci. 11, 4119-4133.

Naber, P.A., da Silva, F.H.L., Witter, M.P., 2001a. Reciprocal connections between the entorhinal cortex and hippocampal fields CA1 and the subiculum are in register with the projections from CA1 to the subiculum. Hippocampus 11, 99-104.

Naber, P.A., Witter, M.P., da Silva, F.H.L., 2001b. Evidence for a direct projection from the postrhinal cortex to the subiculum in the rat. Hippocampus 11, 105-117.

Nagahara, A.H., Otto, T., Gallagher, M., 1995. Entorhinal-perirhinal lesions impair performance of rats on two versions of place learning in the Morris water maze. Behav. Neurosci. 109, 3-9.

Narisawa-Saito, M., Iwakura, Y., Kawamura, M., Araki, K., Kozaki, S., Takei, N., Nawa, H., 2002. Brain-derived neurotrophic factor regulates surface expression of alpha-amino-3-hydroxy-5methyl-4-isoxazoleproprionic acid receptors by enhancing the $\mathrm{N}$-ethylmaleimide-sensitive factor/GluR2 interaction in developing neocortical neurons. J. Biol. Chem. 277 (43), 40901-40910.

Neeper, S.A., Gómez-Pinilla, F., Choi, J., Cotman, C., 1995. Exercise and brain neurotrophins. Nature 373, 109.

Neeper, S.A., Gómez-Pinilla, F., Choi, J., Cotman, C.W., 1996. Physical activity increases mRNA for brain-derived neurotrophic factor and nerve growth factor in rat brain. Brain Res. 726, 49-56.
Nilsson, M., Hansson, S., Carlsson, A., Calrsson, M.L., 2007. Differential effects of the N-methyl-D-aspartate receptor antagonist MK-801 on different stages of object recognition memory in mice. Neuroscience 149, 123-130.

O’Keefe, J., Nadel, L., 1978. The Hippocampus as a Cognitive Map. Clarendon Press, Oxford.

Paré, D., deCurtis, M., Llinás, R., 1992. Role of the hippocampal-entorhinal loop in temporal lobe epilepsy: extra- and intracellular study in the guinea pig brain in vitro. J. Neurosci. 12, 1867-1881.

Patterson, S.L., Abel, T., Deuel, T.A.S., Martic, K.C., Rose, J.C., Kandel, E.R., 1996. Recombinant BDNF rescues deficits in basal synaptic transmission and hippocampal LTP in BDNF knockout mice. Neuron 16, 1137-1145.

Patterson, S.L., Grover, L.M., Schwartzkroin, P.A., Bothwell, M., 1992. Neurotrophin expression in rat hippocampal slices: a stimulus paradigm inducing LTP in CA1 evokes increases in BDNF and NT-3 mRNAs. Neuron 9, 1081-1088.

Paxinos, G., Watson, C., 2005. The Rat Brain in Stereotaxic Coordinates, 5th ed. Academic Press, San Diego.

Ramos, J.M., 2002. The perirhinal cortex and long-term spatial memory in rats. Brain Res. 947, 294-298.

Ramos, J.M., Vaquero, J.M.M., 2005. The perirhinal cortex of the rat is necessary for spatial memory retention long after but not soon after learning. Physiol. Behav. 86, 118-127.

Rex, C.S., Lauterborn, J.C., Lin, C.Y., Kramár, E.A., Rogers, G.A., Gall, C.M., Lynch, G., 2006. Restoration of long-term potentiation in middle-aged hippocampus after induction of brain-derived neurotrophic factor. J. Neurophysiol. 96 (2), 677-685.

Rodriguez-Tébar, A., Dechant, G., Barde, Y.A., 1990. Binding of brain-derived neurotrophic factor to the nerve growth factor receptor. Neuron 4, 487-492.

Rolls, E.T., 1996. A theory of hippocampal function in memory. Hippocampus 6, 601-620.

Santi, S., Cappello, S., Riccio, M., Bergami, M., Aicardi, G., Schenk, U., Matteoli, M., Canossa, M., 2006. Hippocampal neurons recycle BDNF for activity-dependent secretion and LTP maintenance. ЕMBO J. 25 (18), 4372-4380.

Schulz, P.E., Cook, E.P., Johnston, D., 1994. Changes in paired-pulse facilitation suggest presynaptic involvement in long-term potentiation. J. Neurosci. 14, 5325-5337.

Scoville, W.B., Milner, B., 1957. Loss of recent memory after bilateral hippocampal lesions. J. Neurol. Neurosurg. Pyschiatr. 20, 11-21.

Squinto, S.P., Stitt, T.N., Aldrich, T.H., Davis, S., Bianco, S.M., Radziejewski, C., Glass, D.J., Masiakowski, P., Furth, M.E., Valenzuela, D.M., Distefano, P.S., Yancopoulos, G.D., 1991. trkB encodes a functional receptor for brain-derived neurotrophic factor and neurotrophin-3 but not nerve growth factor. Cell 65 , 885-893.

Squire, L.R., 1992. Memory and the hippocampus: a synthesis from findings with rats, monkeys, and humans. Psychol. Rev. 99, 195-231.

Squire, L.R., Alvarez, P., 1995. Retrograde amnesia and memory consolidation: a neurobiological perspective. Curr. Opin. Neurobiol. 5, 178-183.

Squire, L.R., Cohen, N.J., Nadel, L., 1984. The medial temporal regions and memory consolidation: a new hypothesis. In: Weingartner, H., Parker, E. (Eds.), Memory Consolidation. Erlbaum, Hillsdale, New Jersey, pp. 185-210.

Suen, P.C., Wu, K., Levine, E.S., Mount, H.T., Xu, J.L., Lin, S.Y., Black, I. B., 1997. Brain-derived neurotrophic factor rapidly enhances phosphorylation of the postsynaptic N-methyl-D-aspartate receptor subunit 1. Proc. Natl. Acad Sci. U. S. A. 94 (15), 8191-8195.

Swanson, L.W., Cowan, W.M., 1977. An autoradiographic study of the organization of the efferent connections of the hippocampal formation in the rat. J. Comp. Neurol. 172, 49-84.

Van Groen, T., Wyss, J.M., 1990. Extrinsic projections from area CA1 of the rat hippocampus: olfactory, cortical, subcortical, 
and bilateral hippocampal formation projections. J. Comp. Neurol. 302, 515-528.

Vignes, M., Collingridge, G.L., 1997. The synaptic activation of kainate receptors. Nature 388, 179-182.

Wetmore, C., Olson, L., Bean, A.J., 1994. Regulation of brain-derived neurotrophic factor (BDNF) expression and release from hippocampal neurons is mediated by non-NMDA type glutamate receptors. J. Neurosci. 14, 1688-1700.

Widenfalk, J., Olson, L., Thorén, P., 1999. Deprived of habitual running, rats downregulate BDNF and TrkB messages in the brain. Neurosci. Res. 34, 125-132.

Wiig, K.A., Burwell, R.D., 1998. Memory impairment on a delayed non-matching-to-position task after lesions of the perirhinal cortex in the rat. Behav. Neurosci. 112, 827-838.

Winters, B.D., Bussey, T.J., 2005a. Transient inactivation of perirhinal cortex disrupts encoding, retrieval, and consolidation of object recognition memory. J. Neurosci. 25, 52-61.

Winters, B.D., Bussey, T.J., 2005b. Glutamate receptors in perirhinal cortex mediate encoding, retrieval, and consolidation of object recognition memory. J. Neurosci. 25, 4243-44251.

Woolley, M.L., Waters, K.A., Gartlon, J.E., Lacroix, L.P., Jennings, C., Shaughnessy, F., Ong, A., Pemberton, D.J., Harries, M.H., Southam, E., Jones, D.N., Dawson, L.A., 2009. Evaluation of the pro-cognitive effects of the AMPA receptor positive modulator, 5-(1-piperidinylcarbonyl)-2,1,3-benzoxadiazole (CX691), in the rat. Psychopharmacology (Berl). 202 (1-3), 343-354.

Wöhrl, R., Eisenach, S., Manahan-Vaughan, D., Heinemann, U., von Haebler, D., 2008. Acute and Long-term Effects of MK-801 on Direct Cortical Input Evoked Homosynaptic and Heterosynaptic Plasticity in the CA1 Region of the Female Rat.

Wozny, C., Knopp, A., Lehmann, T.N., Heinemann, U., Behr, J., 2005. The subiculum: a potential site of ictogenesis in human temporal lobe epilepsy. Epilepsia 46, 17-21.

Wozny, C., Maier, N., Schmitz, D., Behr, J., 2008. Two different forms of long-term potentiation at CA1-subiculum synapses. J. Physiol. 586, 2275-2734.

Wu, J., Rush, A., Rowan, M.J., Anwyl, R., 2001. NMDA receptor- and metabotropic glutamate receptor-dependent synaptic plasticity induced by high-frequency stimulation in the rat dentate gyrus in vitro. J. Physiol. 533, 745-755.

Wu, K., Len, G.W., McAuliffe, G., Ma, C., Tai, J.P., Xu, F., Black, I.B., 2004. Brain-derived neurotrophic factor acutely enhances tyrosine phosphorylation of the AMPA receptor subunit GluR1 via NMDA receptor-dependent mechanisms. Brain Res. Mol. Brain Res. 130 (1-2), 178-186.

Wu, L.G., Saggau, P., 1994. Presynaptic calcium is increased during normal synaptic transmission and paired-pulse facilitation, but not in long-term potentiation in area CA1 of hippocampus. J. Neurosci. 14, 645-654.

Zafra, F., Hengerer, B., Leibrock, J., Thoenen, H., Lindholm, D., 1990. Activity dependent regulation of BDNF and NGF mRNAs in the rat hippocampus is mediated by non-NMDA glutamate receptors. EMBO J. 9 (11), 3545-3550.

Zafra, F., Lindholm, D., Castrén, E., Hartikka, J., Thoenen, H., 1992. Regulation of brain-derived neurotrophic factor and nerve growth factor mRNA in primary cultures of hippocampal neurons and astrocytes. J. Neurosci. 12 (12), 4793-4799. 